\title{
Performance of indirect immunofluorescence assay, immunochromatography assay and reverse transcription-polymerase chain reaction for detecting human respiratory syncytial virus in nasopharyngeal aspirate samples
}

\author{
LRA Vaz-de-Lima $/{ }^{1}$, MCO Souza/ $/{ }^{1}$, TK Matsumoto $/{ }^{1}$, MA Hong/ ${ }^{1}$, MM Salgado/ $/{ }^{1}$, ML Barbosa/ $/$, \\ NS Sato/ ${ }^{1}$, HI Requejo/ ${ }^{1}$, CAF Oliveira/ ${ }^{1}$, R Pecchini ${ }^{2} /{ }^{3}$, E Berezin ${ }^{2} /{ }^{3}$, SD Passos ${ }^{2} / 4$, C Schvartsman $2 / 5$, \\ A Pasmanick ${ }^{2} / 5$, EL Durigon $/{ }^{1 / 6}, \mathrm{M}$ Ueda $/{ }^{1 /+}$
}

Divisão de Biologia Médica ${ }^{1}$ Rede Diversidade Genômica de Vírus, Instituto Adolfo Lutz, Av. Dr. Arnaldo 351, 10ª andar, 01296-902 São Paulo, SP, Brasil ${ }^{2}$ Clinical Team Work, ${ }^{3}$ Irmandade Santa Casa de Misericórdia de São Paulo, São Paulo, SP, Brasil ${ }^{4}$ Hospital Universitário, Faculdade de Medicina de Jundiaí, Jundiaí, SP, Brasil ${ }^{5}$ Instituto da Criança, Faculdade de Medicina ${ }^{6}$ Instituto de Ciências Biomédicas, Universidade de São Paulo, São Paulo, Brasil

Comparison of the use of indirect immunofluorescence assay (IFA), immunochromatography assay (ICA-BD) and reverse transcription-polymerase chain reaction (RT-PCR) for detecting human respiratory syncytial virus (HRSV) in 306 nasopharyngeal aspirates samples (NPA) was performed in order to assess their analytical performance. By comparing the results obtained using ICA-BD with those using IFA, we found relative indices of $85.0 \%$ for sensitivity and $91.2 \%$ for specificity, and the positive (PPV) and negative (NPV) predictive values were $85.0 \%$ and $91.2 \%$, respectively. The relative indices for sensitivity and specificity as well as the PPV and NPV for RT-PCR were $98.0 \%, 89.0 \%, 84.0 \%$ and $99.0 \%$, respectively, when compared to the results of IFA. In addition, comparison of the results of ICA-BD and those of RT-PCR yielded relative indices of $79.5 \%$ for sensitivity and $95.4 \%$ for specificity, as well as PPV and NPV of $92.9 \%$ and $86.0 \%$, respectively. Although RT-PCR has shown the best performance, the substantial agreement between the ICA-BD and IFA results suggests that ICA-BD, also in addition to being a rapid and facile assay, could be suitable as an alternative diagnostic screening for HRSV infection in children.

Key words: HRSV - IFA - immunochromatography assay - RT-PCR

Human respiratory syncytial virus (HRSV) is the major cause of severe lower respiratory tract disease in children (Law et al. 2002, Simoes \& Carbonell-Estrany 2003, Reina et al. 2004), and been most severe in premature infants and those with congenital immunodeficiency, heart disease and/or bronchopulmonary dysplasia (Welliver 2003). According to WHO (2003), HRSV is responsible for 160,000 deaths per year.

The most common technique for diagnosing HRSV infection is the culturing of respiratory specimens. However, the accuracy of this technique is dependent on the processing and storage conditions of clinical samples, and it is also a burdensome and time-consuming approach (Borek et al. 2006). In the 1990s, with the advent of monoclonal antibodies, indirect immunofluorescence assay (IFA) was employed for detecting viral antigens in nasopharyngeal aspirate samples (NPA), and since then it has often been reported as the most sensitive and rapid testing procedure for identifying HRSV infection (Casia-

Financial support: FAPESP (proc. 2002/08462-9) + Corresponding author: mirthesueda@ial.sp.gov.br Received 15 February 2008

Accepted 7 July 2008
no-Colón et al. 2003, Ohm-Smith et al. 2004). However, this technique requires adequate equipment and highly trained technicians in order to obtain accurate results. Enzyme immunoassays and molecular based techniques such as reverse transcription-polymerase chain reaction (RT-PCR) have been shown to be useful in detecting respiratory viruses in a clinical setting (Dayan et al. 2002, Falsey et al. 2002, 2003, Reina et al. 2004, Shirato et al. 2007). Rapid test kits are also commercially available for detecting specific respiratory viruses such as influenza A\&B and HRSV (Krilov et al. 1994). The rapid and precise diagnosis of HRSV is crucial for the management of the patient so as to provide appropriate treatment and to avoid the misuse of antibiotics as well as to quarantine the infected patients to prevent nosocomial virus spreading and transmission (Hall 2001).

The aim of the present study is to compare the performance of rapid immunochromatography assay (ICABD) and RT-PCR with that of IFA in detecting HRSV in NPA collected from children during the respiratory virus season, in São Paulo and Jundiaí cities, state of São Paulo, Brazil.

\section{PATIENTS, MATERIALS AND METHODS}

Specimen collection and processing - Paired samples of nasal swab (NS) and NPA $(\mathrm{n}=306)$ were collected from 306 children under five years old who had presented with acute respiratory illnesses and were admit- 
ted to (i) Instituto da Criança, Faculdade de Medicina, Universidade de São Paulo, (ii) Irmandade Santa Casa de Misericórdia de São Paulo, and (iii) Hospital Universitário, Faculdade de Medicina de Jundiaí, from March 31 th to June 1st, 2006. NPA and NS samples were collected from the children after the written informed consent form had been signed by their respective parents or guardians. The study protocol was approved by the respective Ethics on Research Committees of all of the institutions participating in the investigation. NPA were collected from a nostril before instilling with sterile saline, and another nostril was swabbed. The two NS from each child were placed on ice and brought immediately to the laboratory. Before processing, NPA and NS samples were pooled and subjected to three methods of diagnostic testing. For the first test, approximately $1.5 \mathrm{~mL}$ of each freshly pooled sample were centrifuged at 1,500 $\mathrm{rpm} / 10$ min (Eppendorf, 5810R Hamburg, Germany), and washed twice with PBS 0.01M pH 7.2. The cell pellet was then resuspended with $500 \mu \mathrm{L}$ of PBS, spotted onto an 8-well slide for IFA (Knittel, Germany), and fixed with nonhydrous acetone at $4^{\circ} \mathrm{C} / 10 \mathrm{~min}$. For the 2 nd test, aliquots of $300 \mu \mathrm{L}$ of fresh sample were taken for testing on ICA-BD. For the 3rd test, $250 \mu \mathrm{L}$ of the sample were added to $750 \mu \mathrm{L}$ of Trizol (Invitrogen, Life Technologies, Carlsbad, USA) and kept at $-80^{\circ} \mathrm{C}$ until RNA extraction, and the RNA extracted was later used in RT-PCR.

IFA - Direct detection of HRSV was performed through IFA using specific monoclonal antibodies from a commercially available respiratory viral panel 1 (for HRSV, Influenza A\&B, Parainfluenza 1-3, Adenovirus) screening and identification kit (Light Diagnostic ${ }^{\mathrm{TM}}$, Chemicon International Inc, Temecula, USA) following manufacturer's instructions. The slides made were examined using an epifluorescence microscope (Axiolab, Carl Zeiss, Germany) with a 400X magnification. Although this Light Diagnostic ${ }^{\mathrm{TM}}$ kit has been dedicated to the qualitative confirmation of respiratory viruses in cell cultures, it was used in the present study to detect HRSV and other respiratory viruses directly in pooled NPA and NS samples, as described by Zheng et al. (2004). The following fluorescent staining patterns were observed for reporting positive fluorescence reactivity: (i) intracellular fluorescence with cytoplasm staining for HRSV and parainfluenza, (ii) staining of nucleus or the cytoplasm alone, (iii) or that of both for influenza and adenovirus. Samples yielding $<10$ epithelial cells per spot were rejected. The sample was considered positive for any respiratory virus if three or more cells demonstrated specific fluorescence, negative if no virus-specific fluorescence was detected in at least 20 epithelial cells, and inconclusive if less than 20 epithelial cells were observed. Samples with fewer than three cells showing fluorescent staining were noted as samples with suspected infection. The IFA data were sent back to the clinicians within $24 \mathrm{~h}$ after the respective specimens had been collected.

$I C A-B D$ - The ICA-BD was performed using the Directigen $^{\mathrm{TM}}$ EZ RSV kit (BD, Sparks, USA) following manufacturer's instructions. The average turnaround time for ICA-BD was $15 \mathrm{~min}$.
$R N A$ extraction and RT-PCR - Viral RNA was extracted from the Trizol-treated NPA according to manufacturer's instructions. The RT-PCR assay was carried out using a high-capacity cDNA archive kit (Applied Biosystems, Fester City, USA) following the manufacturer's technical recommendation. cDNA was amplified by using forward $(+)$ primer GAB (5'-YCAYTTTGAAGTGTTCAACTT-3') for $\mathrm{G}$ protein nucleotides 504-524 (Peret et al. 2000), and reverse (-) primer FV (5'-GTTATGACACTGGTATACCAACC-3') for F protein nucleotides 163-186 (Zheng et al. 1996). Reverse (-) primer $\mathrm{F}_{1} \mathrm{AB}$ (5'-CAACTCCATTGTTATTTGCC-3') was used for intergenic G-F region nucleotides 3-22 (Peret et al. 1998) in nested-PCR when necessary. For RT-PCR, $5 \mu \mathrm{L}$ of cDNA were added to a total of $50 \mu \mathrm{L}$ of reaction mixture and amplified using thermocycler MJ-PTC200 (MJ Research Inc, Waltham, USA). Amplicons were visualized by electrophoresis (Bio-Rad, Laboratories, model 200/2.0, Hercules, USA) in $2 \%$ agarose gel (UltraPure agarose, Invitrogen, Carlsbad, USA) and staining with $0.8 \%$ ethidium bromide.

Statistical analysis - The results of ICA-BD and RTPCR were compared to those of IFA. Relative indices for sensitivity, specificity, prevalence, accuracy as well as positive and negative predictive values for ICA-BDHRSV and RT-PCR were determined in relation to IFA, and also for ICA-BD versus RT-PCR (Galen \& Gambino 1975). The efficiency was calculated for each of the aforementioned correlation by applying the kappa $(\kappa)$ index of agreement and testing its consistency (Fleiss 1981), and the values obtained were ranked according to following definitions: values ranging from 0 to $0.2=$ poor agreement; from 0.21 to $0.40=$ slight agreement; from 0.41 to $0.60=$ moderate agreement; from 0.61 to $0.80=$ substantial agreement; and from 0.81 to $1.0=$ almost perfect agreement. Also, the positivity presented by RT-PCR and ICA-BD was compared to that by IFA using the z-test of proportions (Massad et al. 2003).

\section{RESULTS}

A total of 306 paired specimens were tested. HRSV was found to be present in 113 samples by IFA (36.9\%), 113 by ICA-BD (36.9\%), and $132(43.1 \%)$ by RT-PCR. Seventeen samples were found to be positive for HRSV by IFA but negative by ICA-BD assay, whereas 17 other samples were found to be positive by ICA-BD assay but negative by IFA (Table I). Two out of 96 HRSV-positive samples as shown by both IFA and ICA-BD were found negative by RT-PCR after several repeats. Among the 132 HRSV-positive samples as shown by RT-PCR, 17 $(12.9 \%)$ were tested negative by ICA-BD but positive by IFA, and another $11(8.3 \%)$ were found negative by IFA but positive by ICA-BD. Out of $176 \mathrm{HRSV}$-negative samples as shown by IFA and ICA-BD, $10(5.7 \%)$ were tested positive by RT-PCR (Table I).

The comparison between ICA-BD and IFA showed that the relative indices for sensitivity and specificity of ICA-BD were $85.0 \%$ and $91.2 \%$, respectively and the positive predictive value (PPV) and the negative predic- 
tive value (NPV) were $85.0 \%$ and $91.2 \%$, respectively (Table II). The agreement $\kappa$ index for ICA-BD relative to IFA was 0.76 (substantial strength agreement), with $\mathrm{Z}_{\mathrm{o}}=8.0$ and $\mathrm{Z}_{\text {critical }}=1.96(\mathrm{p}<0.001)$. In addition, when comparing RT-PCR with IFA, we observed relative indices for sensitivity and specificity of $98.0 \%$ and $89.0 \%$, respectively, and PPV and NPV of $84.0 \%$ and $99.0 \%$, respectively. The agreement $\kappa$ index for RT-PCR relative to IFA was 0.85 (almost perfect strength agreement), with $\mathrm{Zo}=9.5$ and $\mathrm{Z}_{\text {critical }}=1.96(\mathrm{p}<0.001)$. On the other hand, the comparison between RT-PCR and ICA-BD showed that the relative indices for sensitivity and specificity were $79.5 \%$ and $95.4 \%$, respectively, and PPV and NPV of $92.9 \%$ and $86.0 \%$, respectively. The agreement $\kappa$ index for RT-PCR relative to ICA-BD was 0.77 (substantial agreement), with $\mathrm{Zo}=8.6$ and $\mathrm{Z}_{\text {critical }}=1.96(\mathrm{p}<0.001)$.

Among the six (1.9\%) HRSV-negative samples as shown by both RT-PCR and IFA (Table I) but that were tested positive by ICA-BD, three of them were shown by IFA to be positive for parainfluenza 2, adenovirus, and influenza A, respectively.

\section{TABLE I}

Human respiratory syncytial virus (HRSV) antigens detection by immunochromatography assay (ICA-BD), indirect immunofluorescence assay (IFA), and reverse transcription-polymerase chain reaction (RT-PCR) in 306 nasal swab and nasopharyngeal aspirate pooled samples

\begin{tabular}{lrrr}
\hline & \multicolumn{3}{c}{ ICA-BD HRSV } \\
\cline { 2 - 4 } & Positive & Negative & Total \\
\hline HRSV IFA positive & & & \\
RT-PCR HRSV positive & 94 & 17 & 111 \\
RT-PCR HRSV negative & 2 & 0 & 2 \\
HRSV IFA negative & & & \\
RT-PCR HRSV positive & 11 & 10 & 21 \\
RT-PCR HRSV negative & 6 & 166 & 172 \\
\hline Total & 113 & 193 & 306 \\
\hline
\end{tabular}

\section{DISCUSSION}

NPA collected during the HRSV season in São Paulo, Brazil (March-June) were evaluated. The presence of HRSV in NPA can be detected by several methods such as the IFA and virus isolation in cell lineage cultures, and the latter has been considered a reference assay for detecting the virus either in samples from adults or those from young children. The culture technique requires a fully equipped laboratory with skilled professionals and has a long turnaround time. Similarly, IFA is also technically challenging and requires equipment with high accuracy and prompt specimen processing (Halstead et al. 1990, Borek et al. 2006).

The technical limitations of viral culture and IFA prompted us to perform this study in which we evaluated a commercially available ICA-BD to determine if it can be used as an alternative diagnostic method for detecting HRSV infection. The $\kappa$ index of 0.76 relative to IFA showed that the results obtained by ICA-BD were in substantial agreement with those obtained by IFA. In order to confirm the discordant results obtained by IFA versus those by ICA-BD, we performed RT-PCR. As previously reported (Falsey et al. 2002, 2003, Kuroiwa et al. 2004), RT-PCR yields the best result (43.1\% of positivity for HRSV vs. $36.9 \%$ by IFA and $36.9 \%$ by ICA-BD). Six samples that were tested positive by ICA-BD (1.9\%) are false-positives as they were shown to be HSRV-negative by both RT-PCR and IFA, and three of them showed positive results for parainfluenza 2 , adenovirus, and influenza A by IFA, respectively. Neither blood contamination nor high viscosity was observed in these samples, and no other cross reactivity-inducing factors in ICA$\mathrm{BD}$ could be elucidated. By using an immunomembrane filter-based rapid test, Reina et al. (2004) found that $0.25 \%$ of all samples (representing $0.7 \%$ of HRSV-positive NPA) were true false-positives. On the other hand, two samples that were tested negative by RT-PCR were tested positive by both IFA and ICA-BD, presumably due to inhibition of polymerization during PCR process-

\section{TABLE II}

Immunochromatography assay (ICA-BD), immunofluorescence assay (IFA) and reverse transcription-polymerase chain reaction (RT-PCR) performance for detecting human respiratory syncytial virus (HRSV) in 306 nasal swab and nasopharyngeal aspirate pooled samples

\begin{tabular}{|c|c|c|c|c|c|c|c|}
\hline \multirow[b]{2}{*}{ Compared Assays } & \multirow[b]{2}{*}{ Sensitivity } & \multirow[b]{2}{*}{ Specificity } & \multicolumn{2}{|c|}{ Predictive value } & \multirow[b]{2}{*}{$\kappa^{a}$} & \multirow[b]{2}{*}{$Z^{b}$} & \multirow[b]{2}{*}{$\mathrm{Z}$ critical } \\
\hline & & & Positive & Negative & & & \\
\hline ICA-BD x IFA & $85.0 \%$ & $91.2 \%$ & $85.0 \%$ & $91.2 \%$ & $\begin{array}{c}0.76 \\
\text { substantial } \\
\text { agreement }\end{array}$ & 8.0 & $\begin{array}{c}1.96 \\
(p<0.0010)\end{array}$ \\
\hline IFA x RT-PCR & $98.0 \%$ & $89.0 \%$ & $84.0 \%$ & $99.0 \%$ & $\begin{array}{c}0.85 \\
\text { almost perfect } \\
\text { agreement }\end{array}$ & 9.5 & $\begin{array}{c}1.96 \\
(p<0.0010)\end{array}$ \\
\hline ICA-BD x RT-PCR & $79.5 \%$ & $95.4 \%$ & $92.9 \%$ & $86.0 \%$ & $\begin{array}{c}0.77 \\
\text { substantial } \\
\text { agreement }\end{array}$ & 8.6 & $\begin{array}{c}1.96 \\
(p<0.0010)\end{array}$ \\
\hline
\end{tabular}

$a$ : kappa index of agreement; $b: \mathrm{Z}$ obtained. 
ing. Unfortunately, these two samples could neither be inoculated into cell culture nor analyzed, thus no further data could be generated using these specimens.

The PCR performed in this study identified 10 samples of which the HRSV diagnosis would have been missed by IFA and ICA-BD, and this observation agrees with previously reported data. In a study by Shirato et al. (2007), $20.0 \%$ of HRSV-negative NPA as shown by ICA were tested positive by RT-PCR and RT-LAMP. Nascimento et al. (2008) observed that among the 26 NPA that showed inconclusive results with IFA, five were shown to be HRSV positive by both one-step RT-PCR and semi-nested RT-PCR. As described by other authors, $5.7 \%(10 / 176)$ of probable false-negatives on both IFA and ICA-BD were observed when compared to RT-PCR. These might be occurred due to the presence of small amount of free antigen in the original specimen, or to the timing of the NPA collection regarding to clinical stage of HRSV infection.

In a study by Ohm-Smith et al (2004), which analyzed a small number of pediatric specimens using ICA$\mathrm{BD}$, they found the relative index for sensitivity to be $72.0 \%$ and concluded that this assay was the least sensitive technique for detecting HRSV compared to other rapid immunoassays, IFA and cell cultures. In addition, other studies conducted on larger numbers of pediatric specimens using rapid ICA yielded relative indices for sensitivity ranging from $71.0 \%$ to $89.2 \%$ (Aldous et al. 2004, Reina et al. 2004, Zheng et al. 2004), which agree with the findings of the present study.

Based on the ICA-BD results of the present study and those reported by Ohm-Smith et al. (2004), we believe that the presence of HRSV in NPA could be overlooked if only one technique is used for diagnosis. Therefore, confirming the results using a second assay will help the clinicians with the diagnosis, especially for cases where the results obtained by ICA-BD are negative (Aldous et al. 2004). Furthermore, culturing respiratory specimens in vitro is highly recommended when negative results are obtained by conventional immunoassays.

Nonetheless, at diagnostic facilities that lack the equipment required to perform the conventional immunoassays, viral cell culture and RT-PCR for detecting infections by respiratory viruses (minimally-equipment laboratories, hospitals or emergency rooms in out-patient units), the rapid and easy-to-perform ICA-BD assay is a suitable alternative method for detecting HRSV in NPA. Samples that are tested negative by ICA-BD can then be sent to laboratories equipped to perform the more complicated diagnostic assays to confirm results and to determine if other respiratory viruses are present. This diagnostic strategy is relevant for monitoring patient treatment and to prevent nosocomial virus transmission.

\section{ACKNOWLEDGEMENTS}

To State Secretariat of Health and Instituto Adolfo Lutz for basic supports, Andreza V Suzuki, Fabiane C Cerqueira, Francieli G Piassa, and Andressa C Mariya, for excellent technical helps in conducting this study.

\section{REFERENCES}

Aldous WK, Gerber K, Taggart EW, Thomas J, Tidwell D, Daly JA 2004. A comparison of Binax ${ }^{\mathrm{TM}} \mathrm{NOW}{ }^{\circledR}$ to viral culture and direct fluorescent assay testing for respiratory syncytial virus. Diagn Microbiol Infect Dis 49: 265-268.

Borek AP, Clemens SH, Gaskins VK, Aird DZ, Valsamakis A 2006. Respiratory syncytial virus detection by Remel Xpect, Binax Now RSV, direct immunofluorescent staining, and tissue culture. J Clin Microbiol 44: 1105-1107.

Casiano-Colón AE, Hulbert BB, Mayer TK, Walsh EE, Falsey AR 2003. Lack of sensitivity of rapid antigen tests for the diagnosis of respiratory syncytial virus infection in adults. $J$ Clin Virol 28: 169-174.

Dayan P, Ahmad F, Urtecho J, Novick M, Dixon P, Levine D, Miller S 2002. Test characteristics of the respiratory syncytial virus enzyme-linked immunoabsorbent assay in febrile infants $\leq 60$ days of age. Clin Pediatr (Phila) 41: 415-418.

Falsey AR, Formica MA, Treanor JJ, Walsh EE 2003. Comparison of quantitative Reverse Transcription-PCR to viral culture for assessment of respiratory syncytial virus shedding. J Clin Microbiol 41: 4160-4165.

Falsey AR, Formica MA, Walsh EE 2002. Diagnosis of respiratory syncytial virus infection: Comparison of Reverse TranscriptionPCR to viral culture and serology in adults with respiratory illness. J Clin Microbiol 40: 817-820.

Fleiss JL 1981. The measurement of interrater agreement. In JL Fleiss, Statistical Methods for Rates and Proportions, 2nd ed., John Wiley, New York, p. 212-236.

Galen RS, Gambino SR 1975. Sensitivity, specificity, prevalence, and incidence. In RS Galen, SR Gambino, Beyond Normality: The predictive value and efficiency of medical diagnoses. John Wiley, New York, p. 10-14.

Hall CB 2001. Respiratory syncytial virus and parainfluenza virus. $N$ Engl J Med 344: 1917-1928.

Halstead DC, Todd S, Fritch G 1990. Evaluation of five methods for respiratory syncytial virus detection. J Clin Microbiol 28: 1021-1025.

Krilov LR, Lipson SM, Barone SR, Kaplan MH, Ciamician Z, Harkness SH 1994. Evaluation of a rapid diagnostic test for respiratory syncytial virus (RSV): potential for bedside diagnosis. Pediatrics 93: 903-906.

Kuroiwa Y, Nagai K, Okita L, Ukae S, Mori T, Hotsubo T, Tsutsumi H 2004. Comparison of an immunochromatographic test with multiplex reverse transcription-PCR for rapid diagnosis of respiratory syncytial virus infection. J Clin Microbiol 42: 4812-4814.

Law BJ, Carbonell-Estrany X, Simoes EAF 2002. An update on respiratory syncytial virus epidemiology: a developed country perspective. Respir Med 96 (Suppl. 2): S1-7.

Massad E, Silveira PSP 2003. Disciplina de métodos quantitativos em medicina. Teste Z. Faculdade de Medicina, Universidade de São Paulo. 2003. Available from http://www.usp.br/fm/dim/darwin/ index.php.

Nascimento CA, Leal AL, Souza TS, de Moraes CTP, Comone P, Tenório ECN, Vedovello D, Quinzani RHA, Gilio AE, Vieira SE, Durigon EL, Botosso VF, Sant'Anna OA 2008. One-step reverse transcriptase polymerase chain reaction for the diagnosis of respiratory syncytial virus in children. J Virol Methods 148: 115-119.

Ohm-Smith MJ, Nassos PS, Haller BL 2004. Evaluation of the Binax NOW, BD Directigen, and BD Directigen EZ assays for detection of respiratory syncytial virus. J Clin Microbiol 42: 2996-2999. 
Peret TC, Hall CB, Hammond GW, Piedra PA, Storch GA, Tsou C, Anderson LJ 2000. Circulation patterns of group A and B human respiratory syncytial virus genotypes in five communities in North America. J Infect Dis 181: 1891-1896.

Peret TC, Hall CB, Schnabel KC, Golub JA, Anderson LJ 1998. Circulation patterns of genetically distinct group A and B strains of human respiratory syncytial virus in a community. $J$ Gen Virol 79: 2221-2229.

Reina J, Gonzalez Gárdenas M, Ruiz de Gopegui E, Padilha E, Ballesteros F, Mari M, Munar M 2004. Prospective evaluation of a dot-blot enzyme immunoassay (Directigen RSV) for the antigenic detection of respiratory syncytial virus from nasopharyngeal aspirates of pediatric patients. Clin Microbiol Infect 10: 967-971.

Shirato K, Nishimura H, Saijo M, Okamoto M, Noda M, Tashiro M, Taguchi F 2007. Diagnosis of human respiratory syncytial virus infection using reverse transcription loop-mediated isothermal amplification. J Virol Methods 139: 78-84.
Simoes EA, Carbonell-Estrany X 2003. Impact of severe disease caused by respiratory syncytial virus in children living in developed countries. Pediatr Infect Dis J 22 (Suppl.): S13-18.

Welliver RC 2003. Review of epidemiology and clinical risk factors for severe respiratory syncytial virus infection. $J$ Pediatr 143 (Suppl. 5): S112-117.

WHO - World Health Organization 2003. Initiative for Vaccine Research. United States of America. State of the art of new vaccines, 2003. Available from http://www.who.int/vaccine_research/documents/new-vaccines/en.

Zheng H, Peret TC, Randolph VB, Crowley JC, Anderson LJ 1996. Strain-specific reverse transcriptase PCR assay: means to distinguish candidate vaccine from wild-type strains of respiratory syncytial virus. J Clin Microbiol 34: 334-337.

Zheng X, Quianzon S, Mu Y, Katz BZ 2004. Comparison of two new rapid antigen detection assays for respiratory syncytial virus with another assay and shell vial culture. J Clin Virol 31: 130-133. 